УДК 624.074

МАТЕМАТИЧЕСКОЕ МОДЕЛИРОВАНИЕ РАБОТЫ ДИСКА ПЕРЕКРЫТИЯ, СОСТАВЛЕННОГО ИЗ СБОРНЫХ ЖЕЛЕЗОБЕТОННЫХ ПЛИТ

Канд. техн. наук Е. Г. Стоянов, асп. А. В. Набока

МАТЕМАТИЧНЕ МОДЕЛЮВАННЯ РОБОТИ ДИСКА ПЕРЕКРИТТЯ, СКЛАДЕНОГО ІЗ ЗБІРНИХ ЗАЛІЗОБЕТОННИХ ПЛИТ

Канд. техн. наук Є. Г. Стоянов, асп. А. В. Набока

\title{
MATHEMATICAL MODELING OF THE DISK OVERLAP WORK, COMPOSED OF THE PRECAST REINFORCED CONCRETE SLABS
}

Doct. of techn. sciences E. G. Stoyanov, A. V. Naboka

В статье рассмотрены основные положения расчета и проектирования сборных дисков перекрытий, составленных из сборных железобетонных предварительно напряженных многопустотных плит. Приведены результаты аналитического решения задачи напряженно-деформированного состояния перекрытия и результать расчета методом конечных элементов.

Ключевые слова: напряженно-деформированное состояние, моделирование, коэффициент эффективности, коэффициент приведения, изгибная жесткость, крутильная жесткость, метод конечных элементов. 
У статті розглянуто загальні положення розрахунку $і$ проектування збірних дисків перекриттів, щзо складаються із збірних залізобетонних попередньо напружених багатопустотних плит. Наведено результати аналітичного розв'язання задачі напруженодеформованого стану перекриття та результати розрахунку методом кінцевих елементів.

Ключові слова: напружено-деформований стан, моделювання, коефічієнт ефективності, коефіцієнт приведення, згинальна жорсткість, крутильна жорсткість, метод кінцевих елементів.

We offer to construct flooring from reinforced concrete precast hollow slabs that ensures structural design of several slabs within floor slab instead of convenient beam-type structural design of separate slab within the flooring. Thus, we have quasi-contour design of operation of flooring slab. Flooring, consisting of several beam slabs within flooring cell in question, has finite bending stiffness in longitudinal direction that depends on geometrical and physical-mechanical parameters and also reinforcement of each separate slab. In transverse direction composite flooring slab has almost zero bending stiffness and bears load due to shear rigidity of the joint and torsion resistance of each slab. This arrangement reduces loads, applied to flooring slab. Represented results of calculations and their comparison by analytical and numerical methods (FEM).

Keywords: stress-strain state, modeling, efficiency ratio, rate reduction, flexural stiffness, torsional rigidity, FEM.

Введение. Для сборных железобетонных предварительно напряженных плит перекрытий вопросы экономической эффективности их применения связаны в наибольшей степени с расходом рабочей арматуры. В последнее время формование таких плит производится безопалубочным стендовым методом $[1,2]$, в них с успехом применяется канатная арматура К1400, К1500 (К7), и вопрос экономии дорогостоящей высокопрочной арматуры является весьма актуальным. При этом требования к прочности, трещиностойкости и деформативности не снижаются [3, 4].

\begin{tabular}{llrr}
\multicolumn{1}{c}{ Нами } & \multicolumn{2}{c}{ предлагается } & вариант \\
перекрытия, & в & \multicolumn{1}{c}{ котором } & сборные \\
железобетонные & плиты & работают \\
совместно в составе ячейки диска \\
перекрытия.
\end{tabular}

Преимущества работы плит в виде единого сборного диска рассматривались и ранее [5-7]. При этом отдельные плиты в составе ячейки соединяются между собой по боковым поверхностям продольным швом, исключающим взаимные сдвиги по вертикали.
Анализ последних достижений и публикаций. Рассматривались различные конструктивные схемы сборных дисков (с опиранием на жесткий или податливый контур, с опиранием плит друг на друга по этажной схеме, с соединением плит между собой с помощью закладных деталей в отдельных точках или сплошным продольным швом [7,8], с устройством надбетонки над пустотными плитами [9] и др.). Определенный интерес представляют композитные железобетонные плиты, в которых в качестве вкладышей применены микрокапсулы РСМ, которые адаптируются к температурному режиму и имеют потенциал в энергосбережении [10].

Цель и задачи исследования. Целью настоящего исследования является возможность управления напряженнодеформированным состоянием квазимонолитной ячейки перекрытия, составленной из сборных железобетонных плит.

\section{Основная часть исследования.} Составная ячейка имеет в продольном направлении определенную изгибную жесткость, зависящую от геометрических и физических параметров, a также от 
армирования каждой плиты. В поперечном направлении изгибная жесткость является практически нулевой, а нагрузка воспринимается только за счет сдвиговой жесткости шва и сопротивления плит кручению.

Характер передачи нагрузки и соответствующая схема работы диска перекрытия в поперечном направлении зависит от количества плит в ячейке.

Так, например, для ячейки перекрытия, составленной из двух плит (рис. 1), каждая из них воспринимает погонный крутящий момент

$$
\mathrm{T}=\mathrm{T}_{(2)}=\mathrm{qb}^{2} / 2 .
$$

От крутящего момента плита поворачивается на угол $\varphi$ :

$$
\varphi=\left(\mathrm{T} / \mathrm{GI}_{\mathrm{k}}\right) \cdot \mathrm{f}(\mathrm{x}),
$$

где $\mathrm{f}(\mathrm{x})$ - функция изменения угла поворота по длине плиты;

$$
\begin{aligned}
& \mathrm{G} \text { - модуль сдвига, } \mathrm{G}=0.4 \mathrm{E}_{\mathrm{cm}} ; \\
& \mathrm{I}_{\mathrm{k}}-\text { крутильный момент инерции }
\end{aligned}
$$
сечения плиты.

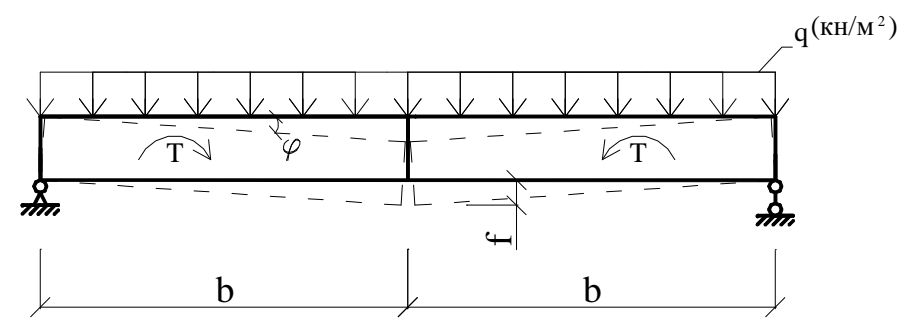

Рис. 1. Схема работы диска перекрытия из двух плит

Крутильный момент инерции определяется в зависимости от наличия, количества и размеров пустот. Так, для сплошного поперечного сечения ее фактическое сечение может быть приведено к пустотелому коробчатому сечению с условной толщиной стенки $t_{\mathrm{ef}}$ [5].

Многопустотную плиту можно рассматривать как многоконтурное сечение. Однако можно принять, что крутильный момент воспринимается полностью внешней оболочкой профиля. В этом случае толщина стенки сечения определяется как $\mathrm{t}_{\mathrm{ef}}=\left(\mathrm{h}-\varnothing_{\text {пустоты }}\right) / 2$.

Для равномерной нагрузки по поверхности диска перекрытия функцию $\mathrm{f}(\mathrm{x})$ можно принять аналогичной функции изменения изгибающего момента по длине плиты. Максимальный угол поворота в центре диска перекрытия

$$
\varphi_{0}=\frac{T}{G h_{k}} \int_{0}^{L}\left(x-\frac{x^{2}}{L}\right) d x=\frac{T L^{2}}{\omega h_{k}} .
$$

Прогиб в центре диска

$$
\mathrm{f}=\mathrm{btg} \varphi_{0}=\mathrm{b} \varphi_{0} .
$$

Погонный изгибающий момент в продольном направлении около шва между плитами

$$
\mathrm{M}=48 \mathrm{E}_{\mathrm{cm}} \mathrm{I}_{\mathrm{z}} \mathrm{f} / 5 \mathrm{~L}^{2}
$$

Если ячейка диска состоит из трех плит, то работу диска можно представить, как показано на рис. 2. 


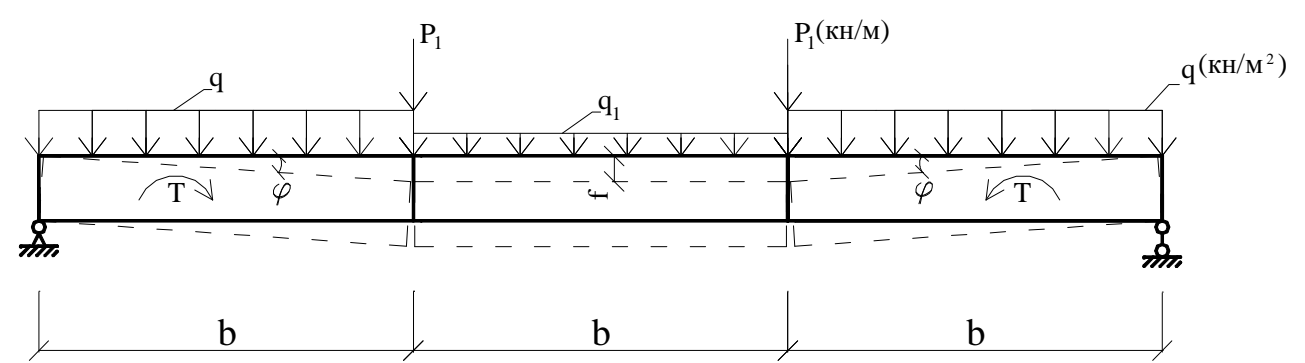

Рис. 2. Схема работы диска перекрытия из трех плит

При этом нагрузка от средней плиты частично распределяется на изгиб плиты, как балочной $\left(\mathrm{q}_{1}\right)$, а частично является погонной линейной нагрузкой на кромку крайней плиты $\mathrm{P}_{1}=\left(\mathrm{q}-\mathrm{q}_{1}\right) \mathrm{b} / 2$, что вызывает дополнительный изгиб крайней плиты от поворота сечения.

Крутящий момент в крайней плите

$$
\mathrm{T}_{(3)}=\mathrm{T}_{(2)}+\mathrm{P}_{1} \mathrm{~b}=\mathrm{qb}^{2}-\mathrm{q}_{1} \mathrm{~b}^{2} / 2 .
$$

Угол поворота крайней плиты

$$
\varphi_{0}=\frac{b^{2} L^{2}}{6 G I_{2}}\left(q-\frac{q_{1}}{2}\right)
$$

прогиб кромки крайней плиты

$$
\mathrm{f}_{\mathrm{\kappa p}}=\mathrm{b} \varphi_{0}=\frac{b^{2} \underline{L}^{2}}{6 G \eta_{\mathrm{k}}}\left(q-\frac{q_{1}}{2}\right) \text {. }
$$

Прогиб средней плиты от ее изгиба по балочной схеме

$$
\mathrm{f}_{\mathrm{cp}}=\frac{5}{3 \mathrm{~g} 4} \cdot \frac{9_{1} b L^{4}}{E_{\mathrm{m}} x_{z}} .
$$

Приравнивая $\mathrm{f}_{\text {кр }}=\mathrm{f}_{\mathrm{cp}}$, получаем

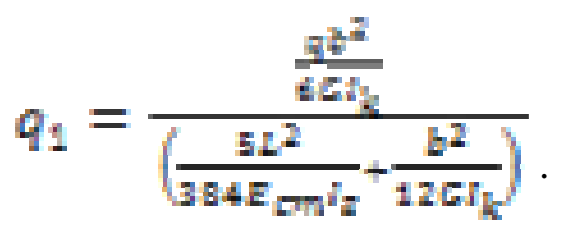

Максимальный прогиб средней плиты при трех плитах в ячейке

$$
f_{(3)}=5 q_{1} b L^{4} / 384 E_{c m} I_{z},
$$

a «балочный» изгибающий момент в средней плите $\mathrm{M}=\mathrm{q}_{1} \mathrm{bL}^{2} / 8$.

Соотношение момента при «балочной» схеме работы одной плиты $\left(\mathrm{M}_{1}\right)$ к моменту в плите сборной ячейки диска перекрытия $\left(\mathrm{M}_{д}\right) \mathrm{n}=\mathrm{M}_{1} / \mathrm{M}_{д}$ является показателем эффективности работы диска перекрытия.

Авторами разработаны алгоритмы расчета и определены коэффициенты эффективности работы дисков перекрытий, составленных из четырех, пяти, шести плит шириной 1.2 м и длиной 6 м, 7.2 м, 9.0 м.

Параллельно с аналитическим решением задачи работы плит в составе диска перекрытия авторами создана конечно-элементная модель диска, составленного из любого количества плит любого пролета под любое нагружение.

Для решения использован программный комплекс ЛИРА-САПР 2013 [6].

Рассматриваемая задача имеет четко выраженный плоский характер, в ЛИРАСАПР 2013 был выбран Признак 3 - схемы, расположенной в плоскости ХОY.

Для всех моделей был принят прямоугольный конечный элемент (КЭ) плиты № 11. Каждый из узлов КЭ имеет три степени свободы: вертикальное перемещение (прогиб), угол поворота 
относительно оси $\mathrm{X}$ и угол поворота относительно оси Y.

Для расчета заданы механические и геометрические характеристики:

- $\mathrm{E}_{\mathrm{cm}}$ - модуль упругости;

- $\mu$ - коэффициент Пуассона, $\mu=0.2$;

- толщина плиты (принята как приведенная $\mathrm{h}=20.88 \mathrm{~cm}$ ).

Собственный вес плиты учитывался в приложенной нагрузке.

Все модели закреплены шарнирно по коротким сторонам. Шарнирное опирание моделировалось путем запрещения перемещений вдоль вертикальной оси Z.

Для КЭ моделей дисков перекрытий из сборных плит шов между плитами моделировался путем создания шарниров с расшивкой узлов.

Модуль $\mathrm{E}_{\mathrm{cm}}$ задается разным для разных плит в составе диска в зависимости от количества плит в диске. Это связано с тем, что первая плита опирается на жесткий контур по трем сторонам, и ее деформации определяются жесткостью на кручение $\mathrm{GI}_{\mathrm{k}}$. Смежные плиты опираются по двум коротким сторонам на жесткие опоры, а по двум длинным сторонам - на упругие контуры (разной упругости на противоположных сторонах). Их деформации определяются в зависимости от факторов и кручения, и изгиба.

Для каждой средней плиты принимается обобщенная жесткость как некоторый конгломерат жесткостей на изгиб $\mathrm{E}_{\mathrm{cm}} \mathrm{I}_{\mathrm{z}}$ и на кручение $\mathrm{GI}_{\mathrm{k}}$, где доля каждого компонента зависит от места каждой средней плиты в составе диска.

Для того чтобы в ПК «ЛИРА-САПР» оперировать единым модулем $\left(\mathrm{E}_{\mathrm{cm}}\right)$, был введен к этому модулю для каждой плиты коэффициент приведения $\mathrm{k}$, который также учитывал снижение жесткости на кручение плиты с пустотами в сравнении со сплошным сечением плиты тех же габаритов на $20 \%$. При этом каждая сборная плита в составе диска рассмотрена как работающая на изгиб с модулем $\mathrm{kE}_{\mathrm{cm}}$.
Функцию изменения коэффициента приведения $\mathrm{k}$ логично принять аналогичной функции упругой линии изгиба диска в поперечном направлении.

Нами принята функция $\mathrm{k}$ в виде синусоиды

$$
\mathrm{k}=\mathrm{y}=\sin \frac{\pi x}{2}
$$

Функцию $\mathrm{k}$ можно принять и в виде полинома, простейший из которых можно представить как

$$
\mathrm{k}=\mathrm{y}=-\frac{4 x^{2}}{l^{2}}+\frac{4 x}{2} .
$$

Обе функции отвечают граничным условиям ( $\mathrm{y}=0$ при $\mathrm{x}=0$ и при $\mathrm{x}=\mathrm{L})$ и условию для средней плиты при нечетном количестве плит в диске $(\mathrm{k}=1$ при $\mathrm{x}=\mathrm{L} / 2)$. Функция (12) имеет более пологий характер, поэтому, на наш взгляд, больше отвечает действительной работе диска.

Если в качестве координат принять центр ширины плит (при ширине плит 1200 мм имеем $\mathrm{X}_{1}=0.6 \mathrm{M} ; \mathrm{X}_{2}=1.8 \mathrm{м}$; $\mathrm{x}_{3}=3.0 \mathrm{M}$ ), то числовые значения коэффициентов приведения, как характеристики моделей дисков, могут быть сведены в табл. 1.

Для сравнения была создана модель сплошной монолитной железобетонной плиты тех же размеров, что и сборный диск. Плита имеет жесткость, эквивалентную изгибной жесткости сборных плит. Сборные и монолитная плиты смоделированы прямоугольными КЭ № 11, размеры всех элементов $0.2 \times 0.2 \mathrm{м}$. Для модели монолитного диска использовано 703 узла и 648 элементов.

В результате расчетов получены поля и эпюры перемещений вдоль вертикальной оси, поля изгибающих моментов $\mathrm{M}_{\mathrm{x}}$ (вдоль длины плит), величины максимальных изгибающих моментов в средних сечениях ячейки диска перекрытия для разных 
значений пролетов и разного количества плит в ячейке.

Сравнение результатов расчетов аналитическим методом и методом конечных элементов показало достаточную степень совпадения для всех параметров напряженно-деформированного состояния при разных пролетах и разном количестве плит (рис. 3).

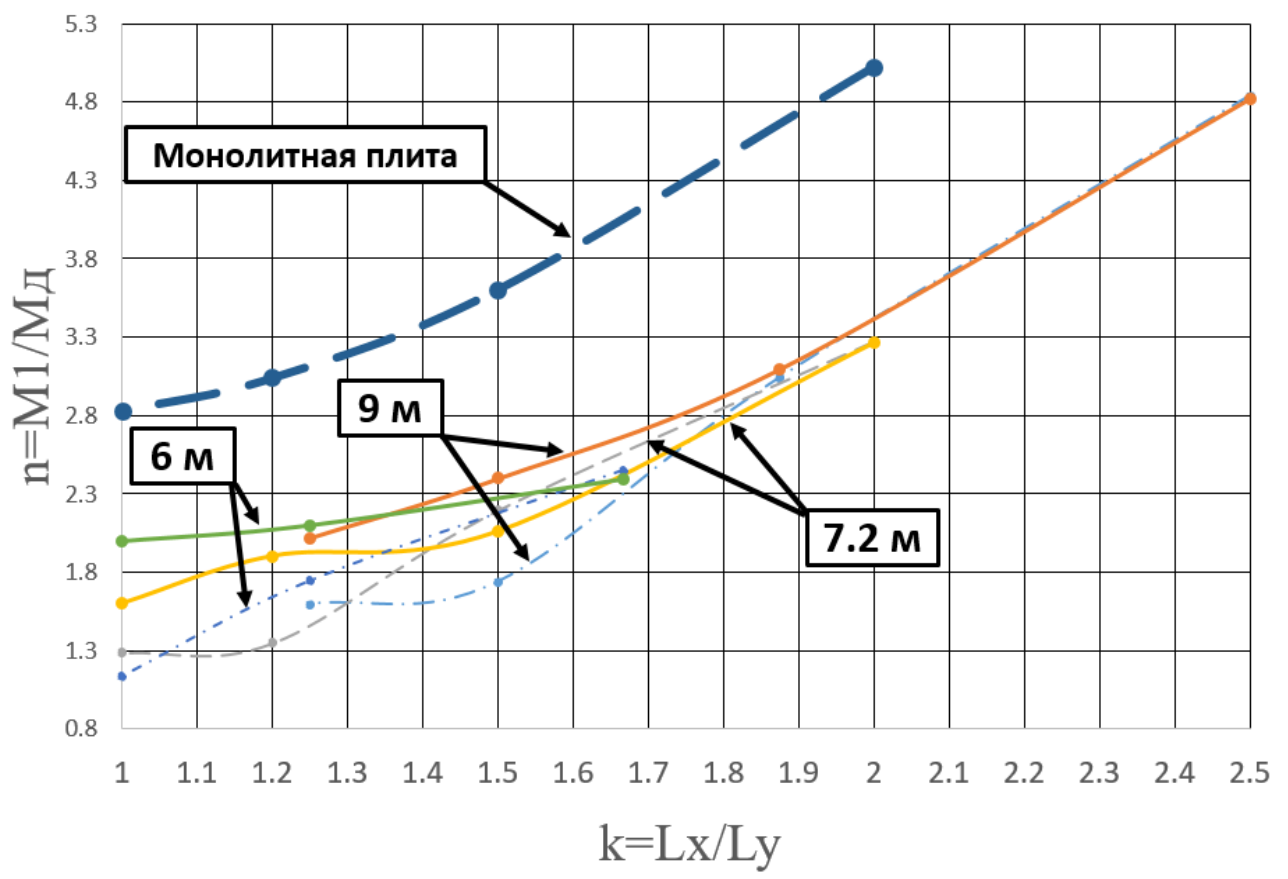

Рис. 3. График $\boldsymbol{n}-\boldsymbol{k}$ изменения изгибающих моментов в диске перекрытия:

$\mathrm{L}_{\mathrm{x}}$ - длина диска (плиты);

$\mathrm{L}_{\mathrm{y}}$ - ширина диска из нескольких плит;

$\mathrm{M}_{1}$ - максимальный момент для одиночной плиты;

$\mathrm{M}_{\text {д }}$ - максимальный момент в плите, работающей в составе диска;

_ • _ - результаты, полученные методом КЭ;

- результаты, полученные аналитическим путем

Уровень снижения величины изгибающих моментов в каждой отдельной плите, работающей в едином диске перекрытия при разных пролетах плит, разном их количестве в диске (разной ширине ячейки диска), разной переменной нагрузке, иллюстрируется в табл. 2.
Выводы по результатам исследования и перспективы по дальнейшему развитию данного направления:

1. Варьирование количеством плит в ячейке перекрытия и их длиной позволяет получить желаемые величины изгибающих моментов в сборных дисках, и, следовательно, возможность управления напряженно-деформированным состоянием перекрытия в целом.

2. Возможность управления напряженным состоянием диска перекрытия позволяет существенно снизить расход арматуры. 
Таблица 1

Характеристика моделей дисков перекрытий из сборных плит

\begin{tabular}{|c|c|c|c|c|c|c|c|c|c|}
\hline $\begin{array}{c}\text { Пролет, } \\
\text { м }\end{array}$ & $\begin{array}{c}\text { Количество } \\
\text { плит }\end{array}$ & $\begin{array}{c}\text { Кол-во } \\
\text { узлов }\end{array}$ & $\begin{array}{c}\text { Количество } \\
\text { елементов }\end{array}$ & \multicolumn{6}{|c|}{$\begin{array}{c}\text { Коеффициєнт приведения k } \\
\text { при х }=0.6 \text { м, } 1.8 \text { м, } 3.0 \text { м }\end{array}$} \\
\hline \multirow{6}{*}{6.0} & 1 & 217 & 180 & & & 1.0 & & & \\
\hline & 2 & 465 & 380 & & & 0.57 & 0.57 & & \\
\hline & 3 & 651 & 540 & & 0.4 & 1.0 & 0.4 & & \\
\hline & 4 & 868 & 720 & & 0.31 & 0.83 & 0.83 & 0.31 & \\
\hline & 5 & 1116 & 900 & 0.25 & 0.73 & 1.0 & 0.73 & 0.25 & \\
\hline & 6 & 1302 & 1080 & 0.21 & 0.57 & 0.77 & 0.77 & 0.57 & 0.21 \\
\hline \multirow{6}{*}{7.2} & 1 & 259 & 216 & & & 1.0 & & & \\
\hline & 2 & 555 & 504 & & & 0.57 & 0.57 & & \\
\hline & 3 & 777 & 648 & & 0.4 & 1.0 & 0.4 & & \\
\hline & 4 & 1036 & 864 & & 0.31 & 0.83 & 0.83 & 0.31 & \\
\hline & 5 & 1295 & 1080 & 0.25 & 0.73 & 1.0 & 0.73 & 0.25 & \\
\hline & 6 & 1554 & 1296 & 0.21 & 0.57 & 0.77 & 0.77 & 0.57 & 0.21 \\
\hline \multirow{6}{*}{9.0} & 1 & 322 & 270 & & & 1.0 & & & \\
\hline & 2 & 690 & 540 & & & 0.57 & 0.57 & & \\
\hline & 3 & 966 & 810 & & 0.4 & 1.0 & 0.4 & & \\
\hline & 4 & 1288 & 1080 & & 0.31 & 0.83 & 0.83 & 0.31 & \\
\hline & 5 & 1610 & 1350 & 0.25 & 0.73 & 1.0 & 0.73 & 0.25 & \\
\hline & 6 & 1932 & 1620 & 0.21 & 0.57 & 0.77 & 0.77 & 0.57 & 0.21 \\
\hline
\end{tabular}

Таблица 2

Изгибающие моменты в сборном диске перекрытия

\begin{tabular}{|c|c|c|c|c|c|c|}
\hline \multirow{2}{*}{$\begin{array}{c}\text { Длина } \\
\text { плиты, } \\
\text { м }\end{array}$} & \multirow{2}{*}{$\begin{array}{c}\text { Переменная } \\
\text { расчетная } \\
\text { нагрузка, } \\
\text { кН/м² }\end{array}$} & \multirow{2}{*}{$\begin{array}{c}\text { Момент в } \\
\text { балочной } \\
\text { плите } \mathrm{M}_{1} \text {, } \\
\text { кНм }\end{array}$} & \multicolumn{4}{|c|}{$\begin{array}{c}\text { Максимальный момент в центре диска } \mathrm{M}_{\text {д }} \text { кНм, } \\
\text { при ширине ячейки перекрытия, м }\end{array}$} \\
\hline & & & 3.6 & 4.8 & 6.0 & 7.2 \\
\hline \multirow{5}{*}{6.0} & 21.0 & 124.5 & 51.9 & 59.3 & 62.2 & - \\
\hline & 16.0 & 98.9 & 41.2 & 47.1 & 49.5 & - \\
\hline & 12.5 & 81.0 & 33.7 & 38.6 & 40.5 & - \\
\hline & 10.0 & 68.2 & 28.4 & 32.5 & 34.1 & - \\
\hline & 8.0 & 58.0 & 24.2 & 27.6 & 29.0 & - \\
\hline \multirow{5}{*}{7.2} & 16.0 & 143.7 & 44.0 & 69.8 & 75.6 & 89.4 \\
\hline & 12.5 & 117.7 & 36.0 & 57.2 & 62.0 & 73.1 \\
\hline & 10.0 & 99.1 & 30.3 & 48.1 & 52.1 & 61.9 \\
\hline & 8.0 & 89.2 & 27.3 & 43.3 & 46.9 & 55.8 \\
\hline & 6.0 & 69.4 & 21.2 & 33.7 & 36.5 & 43.4 \\
\hline \multirow{4}{*}{8.4} & 10.0 & 134.5 & 38.0 & 49.5 & 66.3 & 78.8 \\
\hline & 8.0 & 121.0 & 34.1 & 44.5 & 59.6 & 71.2 \\
\hline & 6.0 & 94.1 & 26.5 & 34.6 & 46.3 & 55.3 \\
\hline & 4.5 & 79.0 & 22.3 & 29.1 & 38.9 & 46.5 \\
\hline \multirow{3}{*}{9.0} & 8.0 & 139.4 & 28.9 & 45.0 & 58.1 & 69.0 \\
\hline & 6.0 & 108.4 & 22.5 & 35.0 & 45.2 & 53.5 \\
\hline & 4.5 & 91.0 & 18.9 & 29.4 & 37.9 & 45.1 \\
\hline
\end{tabular}




\section{Список использованных источников}

1. Шмуклер, В. С. Особенности внедрения железобетонных многопустотных предварительно напряженных плит перекрытий безопалубочного стендового формования [Текст] / В. С. Шмуклер, Е. Г. Стоянов, О. М. Пустовойтова и др. // Комунальне господарство міст. - Харків, 2014. - №114. - С. 22-30.

2. Стоянов, Е. Г. Особенности проектирования многопустотных плит с напрягаемой канатной арматурой [Текст] / Е. Г. Стоянов, А. В. Набока // Комунальне господарство міст. Харків, 2015. - № 123. - С. 12-18.

3. ДБН В.2.6-98:2009. Бетонні та залізобетонні конструкції. Основні положення [Текст]. - К.: Мінрегіонбуд України, 2009.

4. ДСТУ Б В.2.6-156:2010. Бетонні та залізобетонні конструкції з важкого бетону. Правила проектування [Текст]. - К.: Мінрегіонбуд України, 2010.

5. Байков, В. Н. Проектирование железобетонных тонкостенных пространственных конструкцій / В. Н. Байков, Э. Хампе, Э. Рауэ. - М.: Стройиздат, 1990. - 232 с.

6. Шмуклер, В. С. Каркасные системы облегченного типа [Текст] / В. С. Шмуклер, Ю. А. Климов, Н. П. Буряк. - Харьков: Золотые страницы, 2008. - 336 с.

7. Стоянов, Е. Г. Экспериментальное исследование работы сборных железобетонных предварительно напряженных плит в составе диска перекрытия [Текст] / Е. Г. Стоянов, А. В. Набока // Науковий вісник будівництва. - Харків: ХНТУБА, 2016. - №1(83). - С. 107114.

8. Krzysztof Gromysz Distribution of forces in composite concrete slabs between the joint and reinforcement anchored on the support [Text] / K. Gromysz // Procedia Engineering. - 2013. Vol. 65. - P. 206-211.

9. Eray Baran Effects of cast-in-place concrete topping of flexural response of precast concrete hollow-core slabs [Text] / E. Baran // Engineering Structures. - 2015. - Vol. 98. - P. 109117.

10. Lidia Navarro Design of prefabricated concrete slab with PCM inside the hollows [Text] / Lidia Navarro, Alvaro de Garcia, Albert Castell, Servando Alvarez, Luisa F. Cabeza // Energy Procedia. - 2014. - Vol. 57. - P. 2324-2332.

11. Бабаєв, В. М. Практичний розрахунок елементів залізобетонних конструкцій за ДБН В 2.6-98:2009 у порівнянні з розрахунками за СНиП 2.03.01-84* і EN 1992-1-1(Eurocode 2) [Текст] / В. М. Бабаєв, А. М. Бамбура, О. М. Пустовойтова [та ін.]. - Харків: Золоті сторінки, 2015. - $206 \mathrm{c}$.

Стоянов Свген Геннадійович, канд. техн. наук, доцент кафедри будівельних конструкцій Харківського національного університету міського господарства ім. О. М. Бекетова. E-mail: kname.edu.ua.

Набока Анатолій Віталійович, аспірант кафедри будівельних конструкцій Харківського національного університету міського господарства ім. О. М. Бекетова. E-mail: kname.edu.ua.

Stoyanov Evgeniy Genadiyovich, d-r science, docent department of building constructions. O.M. Beketov National University of Urban Economy in Kharkov. E-mail: kname.edu.ua.

Naboka Anatoliy Vitalievich graduate student department of building constructions O.M. Beketov National University of Urban Economy in Kharkov. E-mail: kname.edu.ua.

Стаття прийнята 27.02.2017 p. 